\title{
Effects of abscisic acid and brassinolide on photosynthetic characteristics of Leymus chinensis from Songnen Plain grassland in Northeast China
}

\author{
Yong-Jun Hu${ }^{1,2}$, Lian-Xuan Shi ${ }^{1 *}$, Wei Sun ${ }^{1}$ and Ji-Xun Guo ${ }^{1 *}$
}

\begin{abstract}
Background: It has been well demonstrated that plant growth regulators have important functions in multiple physiological processes. ABA and BR play crucial roles in response of crops to stresses. Photosynthetic capacity of Leymus. chinensis treated by various concentrations of ABA and BR in combination was determined. Further more, the mechanisms of $A B A$ and $B R$ treatments and potential for recovery of saline-alkali grasslands were discussed.

Results: Abscisic acid (ABA) and brassinolide (BR) affected leaf gas exchange, growth and biomass of $L$. chinensis. The application of ABA and BR mixtures, especially that of $0.01 \mathrm{mM} \mathrm{ABA}$ and $2 \times 10^{-4} \mathrm{mM} \mathrm{BR}$, increased the net photosynthetic rate, stomatal conductance, water use efficiency, the maximum net photosynthetic rate, lightsaturated rate, leaf respiration rate, the maximum RUBP carboxylation rate, the maximum electron transport rate, the maximum triose-phosphate utilization, carboxylation efficiency and the quantum efficiency of PSII and subsequently enhanced density, height and biomass in L. chinensis. We also observed reduction in the light compensation and saturation points following the application of ABA and BR treatments.

Conclusions: We concluded that proper use of plant growth regulators can enhance the plant growth and productivity on the Songnen grassland, which is particularly important for the improvement of saline - alkaline grassland and the yield of grazing lands.
\end{abstract}

Keywords: Abscisic acid; Brassinolide; Leymus chinensis; Photosynthetic characteristics; Songnen plain grassland

\section{Background}

It has been well demonstrated that plant growth regulators are involved in multiple physiological processes Krouk et al. (2011). Plant growth regulators are increasingly used for the improvement of plant growth and stress resistance. Recent publications reported the effects of several resistance-related hormones, including salicylic acid, jasmonates, polyamines, and 5-aminolevulinic acid (ALA), etc. on plant physiological activities. As the most studied stress-responsive hormone, abscisic acid (ABA) play crucial roles in response of plants to abiotic stresses such as drought, salinity and frost Wu (2010). For the water-stressed plants, ABA can decrease water loss via transpiration, improve the antioxidant enzymes system, and induce the expression of stress-related

\footnotetext{
*Correspondence: lianxuanshi@nenu.edu.cn; gjixun@nenu.edu.cn

${ }^{1}$ Key Laboratory for Vegetation Ecology, Ministry of Education, Institute of Grassland Science, Northeast Normal University, Changchun 130024, China Full list of author information is available at the end of the article
}

genes. Moreover, exogenous application of ABA significantly influences leaf photosynthesis and photosynthate accumulation through regulating stomata openness and/or activities of photosynthetic enzymes. ABA treatments show complex effects on leaf photosynthesis. Šafránková et al. (2007) found that ABA treatment significantly decreased the net photosynthetic rate $\left(P_{\mathrm{N}}\right)$ and transpiration rate $(E)$ of the water-stressed barley. ABA associated decrease in $P_{\mathrm{N}}$ was also be found in Stylosanthes guianensis Zhou et al. (2006) and Pennisetum typhoides Sankhla and Huber (1974). However, several studies showed positive effects of ABA treatment on leaf photosynthesis McLaren and Smith (1977; Jia and Lu 2003; Li et al. 2006). The compromise results were also be found by Mawson et al. (1981), and Franks and Farquhar (2001). The above mentioned inconsistent results about the effects of ABA on leaf gas exchange may be caused by multiple factors, including 
differences in stress factors, ABA dosage and treatment time McLaren and Smith (1977).

In addition to the inconsistent effects of plant hormone on plant growth performance, the mixture of different plant hormones can produce additive action or counteraction on plant metabolism Peleg and Blumwald (2011). For example, Sankhla and Huber (1974) found that the mixture of abscisic and gibberellic acids tended to antagonize each other in incorporation of ${ }^{14} \mathrm{CO}_{2}$ into photosynthetic products. Brassinolide (BR), another common plant hormone with high biological activity, is found recently in vegetables Khripach et al. (2000). BR treatments have significant effects on plant growth and stress resistance Bajguz and Hazat (2009). BR treatments lead to the increase of net photosynthetic rates Vardhini and Ramr (1998, Hou and Li 2001) or delay the reduction of photosynthetic rate Liu et al. (2008). However, the information on the influence of ABA and BR in combination on leaf photosynthesis is less available.

To date, most studies about ABA and BR are mainly focussed on crops with very few studies on perennial grasses. Leymus chinensis, a perennial grass, is the dominate species in the salinized Songnen grassland in Northeastern China Li and Zheng (1997). The Songnen grassland covers approximately $20-25 \%$ of the total area in Songnen plain and is mainly utilized for hay production and livestock grazing Li and Zheng (1997). The present study was conducted over three years within self-sown L. chinensis populations. Photosynthetic capacity of $L$. chinensis treated by various concentrations of $\mathrm{ABA}$ and $\mathrm{BR}$ in combination was determined. Furthermore, the mechanisms of ABA and BR treatments and potential for recovery of salinealkali grasslands were discussed.

\section{Methods}

Study site and experimental design

This research was conducted at The Grassland Ecosystem Experimental Station of Northeast Normal University, Chang Ling Horse Breeding Farm in Jilin Province $\left(44^{\circ} 30^{\prime}\right.$ to $44^{\circ} 45^{\prime} \mathrm{N}, 123^{\circ} 31^{\prime}$ to $123^{\circ} 56^{\prime} \mathrm{E}$ ), Northeast China. The study area has a typical mesothermal monsoon climate, with an altitude of 37.8 to $144.8 \mathrm{~m}$. The region is cold and dry in spring with frequent wind, warm and wet in summer with frequent drought, early frosts in autumn, and long, cold winters with little snowfall. The mean annual temperature is $5.0^{\circ} \mathrm{C}$ with a frost-free period of 136 to $146 \mathrm{~d}$. The mean annual precipitation is about $450 \mathrm{~mm}$ mainly occured from June to August and accounts for over $60 \%$ of the annual precipitation. The annual evaporation is 2 to 3 times higher than precipitation. Salinized meadow soil is the main soil type in the Songnen grassland.
Seven plots were selected for sampling. Each plot area was $10 \times 10 \mathrm{~m}$ with a $2 \mathrm{~m}$ isolation belt between plots. The L. chinensis community in the selected area had been established for two years by artificial seeding. The plants of $L$. chinensis were uniform in size with almost no weeds. Seven treatments were applied (Table 1).

$\mathrm{ABA}$ and $\mathrm{BR}$ were sprayed during the middle ten days of May in 2005 and 2006, respectively. Fully expanded leaves of plants from each plot were used to measure photosynthetic characteristics. The density, height, and biomass of the $L$. chinensis community were determined using standard sampling methods Shi and Guo (2006), and each measurement was repeated 5 times.

$P_{\mathrm{N}}, g_{\mathrm{s}}, C_{\mathrm{i}} / C_{\mathrm{a}}$, and $E$ were determined using a portable open flow gas exchange system LI-6400XT (LI-COR, USA) at $2 \mathrm{~h}$ intervals from 8:00 $\mathrm{h}$ to 16:00 h. WUE was calculated as $P_{\mathrm{N}} / E$. The photosynthetically active radiation (PAR) was $1000 \pm 12 \mu \mathrm{mol} \mathrm{m}{ }^{-2} \mathrm{~s}^{-1}, \mathrm{CO}_{2}$ concentration was $350 \pm 2 \mathrm{ppm}$, and leaf temperature was $26.0 \pm$ $0.8^{\circ} \mathrm{C}$. Gas exchange was measured on fully expanded leaves from the same adult plants for five plants per plot. Measurements were repeated three times for each selected plant. Moreover, measurements were done within three consecutive days in mid-July.

\section{The responses of photosynthesis to light $(A / Q)$}

For the measurement of $A / Q$, the photosynthetic photon flux density levels used for the construction of light response curves were: 2000, 1800, 1600, 1400, 1200, 1000, $800,600,400,200,100,50$ and $0 \mu \mathrm{mol} \mathrm{m} \mathrm{s}^{-2}$ generated by a LI-6400/02B red/blue light source Wu et al. (2007). The $\mathrm{CO}_{2}$ concentration was kept at $380 \mu \mathrm{mol} \mathrm{mol}{ }^{-1}$ Wang and Zhou (2004). Each measurement was repeated 10 times between 9:00 $\mathrm{h}$ to 12:00 $\mathrm{h}$ in mid-July. All $A / Q$ parameters were determined by fitting data to the quadratic equation described by Prioul and Chartier (1997). QE $\mathrm{Q}_{\mathrm{E}}$ LCP, LSE, $A_{\max }$ were modeled using the linearization of $A / Q$ curves (Long and Bernacchi 2003).

\section{The responses of photosynthesis to $\mathrm{CO}_{2}\left(A / C_{\mathrm{i}}\right)$}

The same process used in $A / Q$ measurements was used for $A / C_{\mathrm{i}}$ curves. A range of $\mathrm{CO}_{2}$ concentrations $\left(C_{\mathbf{i}}\right)$, i.e.

Table 1 Experimental treatments

\begin{tabular}{lc}
\hline Treatment & Concentration $(\mathrm{mM})$ \\
\hline Control & -- \\
$\mathrm{ABA}$ & 0.01 \\
High BR & $2 \times 10^{-4}$ \\
$\mathrm{ABA}+$ low BR & $0.01,0.02 \times 10^{-4}$ \\
$\mathrm{ABA}+$ medium BR & $0.01,0.2 \times 10^{-4}$ \\
ABA + high BR & $0.01,2 \times 10^{-4}$ \\
High ABA + high BR & $0.1,2 \times 10^{-4}$ \\
\hline
\end{tabular}

ABA: abscisic acid; BR: brassinolide. 
1800, 1600, 1400, 1200, 1000, 800, 600, 400, 200, 100 and $50 \mu \mathrm{mol} \mathrm{mol}^{-1}$ was generated using a $12 \mathrm{~g} \mathrm{CO}_{2} \mathrm{cy}-$ linder, starting from 1800 and ending at $50 \mu \mathrm{mol} \mathrm{mol}^{-1}$. The $A / C_{\mathrm{i}}$ curves were measured under four light gradients: 1200, 1000, 800 and $400 \mu \mathrm{mol} \mathrm{m}{ }^{-2} \mathrm{~s}^{-1}$ Dordas and Sioulas (2007). Leaf temperature was kept at $32 \pm 0.8^{\circ} \mathrm{C}$ and each gradient of light or $\mathrm{CO}_{2}$ concentration treatment was repeated five times between 9:00 $\mathrm{h}$ and 10:00 h. $A_{\text {sat }}$ CCP, Resp, $V_{\text {cmax }}, J_{\text {max }}, V_{\text {TPU }}$ and CE were calculated according to Prioul and Chartier (1997) and Olsson and Leverenz (1994). Leaves were held in the chamber until values of photosynthesis reached a steady state. At $\mathrm{CO}_{2}$ concentration, the analysis of photosynthetic response to $\mathrm{CO}_{2}$ Field et al. (1989, Chen et al. 2006) was accompanied by a match. A model curve described by the rectangular hyperbola Olsson and Leverenz (1994) was fitted.

\section{Chlorophyll fluorescence}

Chlorophyll fluorescence measurements included initial fluorescence $\left(F_{o}\right)$, maximum fluorescence $\left(F_{m}\right)$ and variable fluorescence $\left(F_{v}\right), F_{o}$ refers to fluorescence when PSII reaction center opens entirely. The decrease of $F_{o}$ indicates the increase of antenna hot dissipation; and the increase of $F_{o}$ indicates the uneasy reversing damage of PSII reaction center. $F_{m}$ refers to fluorescence when PSII reaction center closes entirely. A decrease in $F_{m}$ indicates inhibition of photosynthesis. $F_{v}$, the difference between $F_{m}$ and $F_{o}$, reflects a reduction in $Q_{A}$. The first fully expanded, healthy leaves were measured using Li-6400XT (LI-COR, USA) for dark-acclimated and light- acclimated measurements. $F_{o}$ was measured after 20 min of dark acclimation during a low intensity pulsed. $F_{m}$ was recorded in a $0.8 \mathrm{~s}$ pulse of saturating light $\left(6500 \mu \mathrm{mol} \mathrm{m} \mathrm{m}^{-2}\right)$.

\section{Statistical analyses}

All photosynthetic parameters were analyzed using SPSS (v. 11.0 for Windows, USA) and SigmaPlot 10. Photosynthesis Assistant was used to analyze parameters related to responses to light and $\mathrm{CO}_{2}$. The level of statistical significance was $P \leq 0.05$.

\section{Results}

Quantitative changes in plant growth parameters and plant density

Plant density, height, and fresh mass of L. chinensis were significantly affected by ABA and BR treatments (Figure 1). Plant density increased, compared to control, $49.6 \%, 60.7 \%, 60.7 \%, 85.9 \%$ and $76.9 \%$ at $2 \times 10^{-4} \mathrm{mM} \mathrm{BR}$, $0.01 \mathrm{mM}$ ABA and $0.02 \times 10^{-4} \mathrm{mM}$ BR, $0.01 \mathrm{mM} \mathrm{ABA}$ and $0.2 \times 10^{-4} \mathrm{mM}$ BR, $0.01 \mathrm{mM}$ ABA and $2 \times 10^{-4} \mathrm{mM}$ $\mathrm{BR}, 0.1 \mathrm{mM} \mathrm{ABA}$ and $2 \times 10^{-4} \mathrm{mM}$ BR treatments, respectively. Plant height increased $12.7 \%, 25.7 \%, 7.7 \%$, and $9.2 \%$, respectively at $0.01 \mathrm{mM} \mathrm{ABA}$ and $0.02 \times 10^{-4} \mathrm{mM}$ BR, $0.01 \mathrm{mM}$ ABA and $0.2 \times 10^{-4} \mathrm{mM}$ BR, $0.01 \mathrm{mM}$ ABA and $2 \times 10^{-4} \mathrm{mM} \mathrm{BR}, 0.1 \mathrm{mM} \mathrm{ABA}$ and $2 \times 10^{-4} \mathrm{mM} \mathrm{BR}$ treatments. However, plant height decreased $9.4 \%$ and $1.8 \%$ at $\mathrm{ABA}$ alone and $\mathrm{BR}$ alone treatments compared to the control. Plant biomass of the six respective treatments significantly increased 6.5\%, 48.2\%, 64.7\%, $54.6 \%, 98.6 \%$, 95.8\% compared to the control. Various

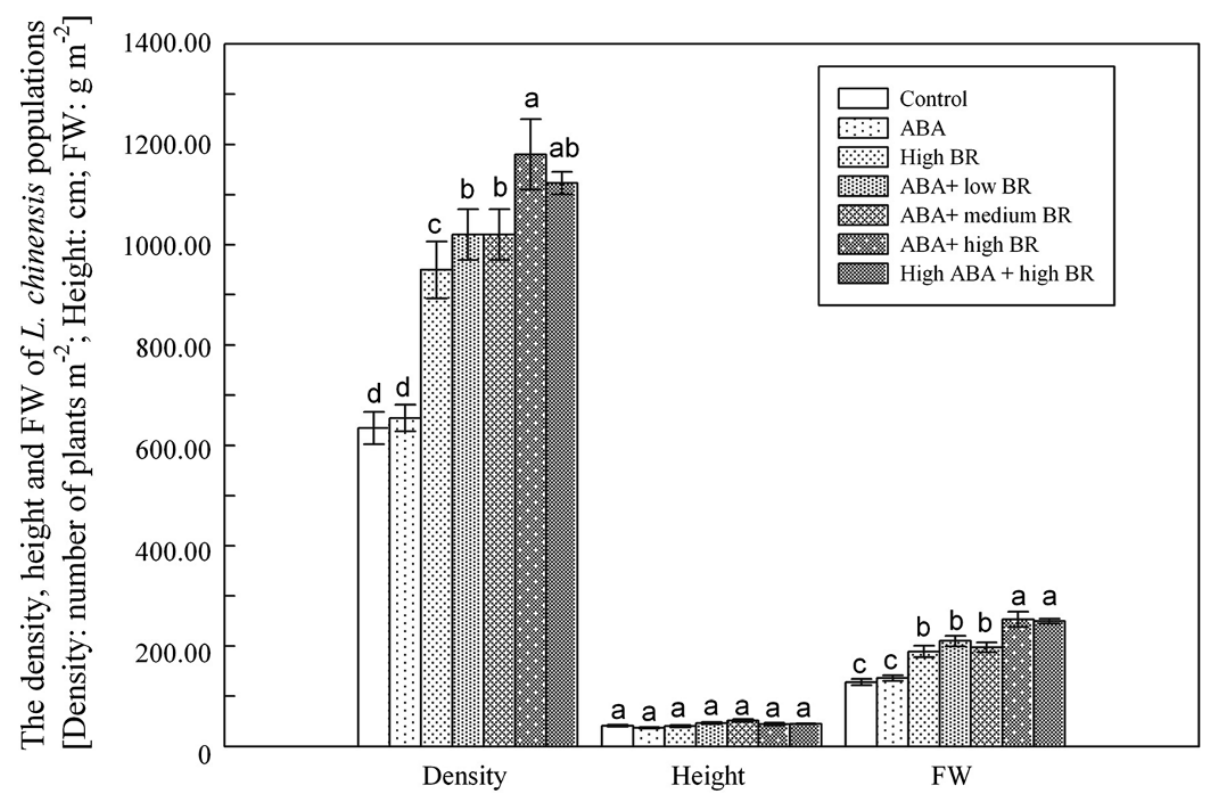

Figure 1 Changes in the density, height and the FWof $L$. chinensis populations under ABA and BR treatments (Density: number of plants $\mathrm{m}^{-2}$; Height: $\mathrm{cm}$; FW: fresh weight $\mathrm{g} \mathrm{m}^{-2}$ ). 
ABA and BR treatments showed significant differences $(P \leq 0.05)$ among treatments for $L$. chinensis leaf characters (Figure 2). For the leaves of single plant, results were in accordance with those for community plant biomass. The length and length/width ratio were significantly different $(P \leq 0.05)$ for $0.01 \mathrm{mM} \mathrm{ABA}$ and $2 \times 10^{-4} \mathrm{mM}$ BR, $0.1 \mathrm{mM}$ ABA and $2 \times 10^{-4} \mathrm{mM} \mathrm{BR}$ treatments, which increased length by $41.3 \%$ and $34.7 \%$, respectively, and width by $28.3 \%$ and $28.2 \%$, respectively, compared to control.

\section{Diurnal patterns of leaf gas exchange}

Diurnal patterns in $P_{\mathrm{N}}$ were similar among treatments and exhibited bimodal curves, reflecting a significant drop at noon (Figure $3 A, P \leq 0.05$ ). The daily average values of $P_{\mathrm{N}}$ showed a upward trend. All treatments were significant higher than the control except the treatment of ABA alone. Notably, the $0.01 \mathrm{mM}$ ABA and $2 \times 10^{-4} \mathrm{mM}$ BR treatment had the highest $P_{\mathrm{N}}$ values among the treatments. There were no apparent differences in diurnal patterns in $g_{\mathrm{s}}$ among the treatments. However, the average value of $g_{\mathrm{s}}$ in $\mathrm{ABA}$ and BR treatments were significantly $(P \leq 0.05)$ higher than the control. Especially, $0.01 \mathrm{mM} \mathrm{ABA}$ and $2 \times 10^{-4} \mathrm{mM}$ BR treatments was significantly $(P \leq 0.05)$ higher than the control and other treatments (each increased on average by $74.0 \%, 45.0 \%, 29.2 \%, 52.2 \%, 18.6 \%$, 29.6\%). (Figure $3 B$ ). Diurnal patterns in $C_{\mathrm{i}} / C_{\mathrm{a}}$ did not differ significantly among treatments, presenting a general stable trend (Figure $3 C$ ). The daily average value of $C_{\mathrm{i}} / C_{\mathrm{a}}$ also did not differ significantly among treatments. The diurnal patterns of $E$ varied greatly among treatments, and at 12:00 h, the hormone treatment significantly $(P \leq 0.05)$ decreased the transpiration rate of $L$. chinensis leaves (Figure 3D). The daily average value of $E$ showed a declining trend from ABA alone treatment to $\mathrm{ABA}$ and high $\mathrm{BR}$ treatment. High $\mathrm{ABA}$ and high $\mathrm{BR}$ treatment increased $E$ but still lower than the control. Each of the treatments was on average lower by $2.1 \%$, $9.6 \%, 14.0 \%, 15.9 \%, 24.4 \%$, and $13.5 \%$ relative to the control. The pattern of daily WUE was similar to those of $P_{\mathrm{N}}$, showing a bimodal curve. At $14: 00 \mathrm{~h}$, the differences among treatments in WUE were the largest, and WUE of $0.01 \mathrm{mM} \mathrm{ABA}$ and $0.2 \times 10^{-4} \mathrm{mM} \mathrm{BR}$, and $0.01 \mathrm{mM}$ ABA and $2 \times 10^{-4} \mathrm{mM}$ BR treatments were significantly $(P \leq 0.05)$ higher than the other treatments (Figure $3 E$ ). The daily mean WUE of $L$. chinensis increased due to treatments, except ABA alone. Treatment of $0.01 \mathrm{mM}$ ABA and $2 \times 10^{-4} \mathrm{mM}$ BR showed the highest WUE, with $80.3 \%, 97.3 \%, 34.1 \%, 72.1 \%, 19.5 \%$, and $25.5 \%$ increases over other treatments.

\section{Photosynthetic response to light $(A / Q)$}

Significant differences in photosynthetic parameters were observed among $\mathrm{ABA}$ and $\mathrm{BR}$ treatments with different concentrations (Table 2). The $\mathrm{Q}_{\mathrm{E}}$ values of $L$. chinensis were increased in treatments compared to the control, $0.01 \mathrm{mM}$ ABA and $2 \times 10^{-4} \mathrm{mM} \mathrm{BR}, 0.1 \mathrm{mM} \mathrm{ABA}$ and $2 \times 10^{-4} \mathrm{mM}$ $\mathrm{BR}$ treatments were significantly higher than others. The $A_{\max }$ of $0.01 \mathrm{mM}$ ABA was lower than the control; the other treatments were higher than the control plots, in particular, $0.01 \mathrm{mM} \mathrm{ABA}$ and $2 \times 10^{-4} \mathrm{mM}$ BR treatment increased $A_{\max }$ by $63.2 \%$. However, LCP and LSE trended to decrease, especially for $0.01 \mathrm{mM} \mathrm{ABA}$ and $2 \times 10^{-4} \mathrm{mM}$ BR, $0.1 \mathrm{mM} \mathrm{ABA}$ and $2 \times 10^{-4} \mathrm{mM}$ BR treatments. The results showed that hormone treatments influenced photosynthetic responses to light.

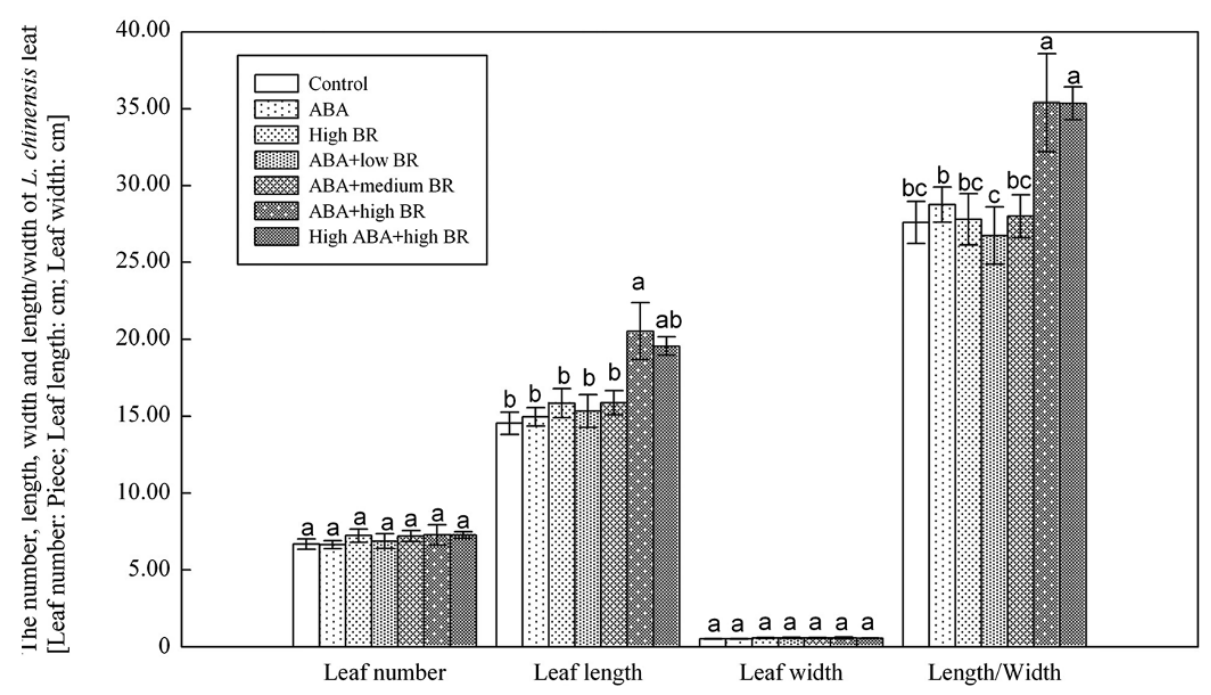

Figure 2 Changes in the number, length, width and length/width of $L$. chinensis leaves under ABA and BR treatments (Leaf number: piece; Length: $\mathrm{cm}$; Width: $\mathrm{cm}$ ). 
Figure 3 Daily changes in photosynthetic parameter of $L$. chinensis under $\mathrm{ABA}$ and $\mathrm{BR}$ treatments. $(A)$ net photosynthetic rate, $P_{N^{\prime}}(\boldsymbol{B})$ stomatal conductance, $g_{\mathrm{s}}(\boldsymbol{C})$ transpiration rate, $E_{\text {, }}$ (D) ratio of stomatal and sub-stomatal $\mathrm{CO}_{2}$ concentrations, $C_{\mathrm{i}} / C_{\mathrm{a}}$, and $(\boldsymbol{E})$ water use efficiency, WUE.

The responses of photosynthesis to $\mathrm{CO}_{2}\left(A / C_{i}\right)$

$\mathrm{CO}_{2}$ compensation point (CCP) were not affected by treatments, but there were significant differences in $A_{\text {sat }}$, $R e s p, V_{\text {cmax }}, J_{\text {max }}, V_{\text {TPU }}, C E$ among treatments (Table 3 ). $A_{\text {sat }}$ and Resp showed no obvious change occurred between the ABA and the BR treatments versus the control, but the values under ABA and BR combined treatments were higher than that of the control, especially the $0.01 \mathrm{mM} \mathrm{ABA}$ and $2 \times 10^{-4} \mathrm{mM}$ BR treatment, increased $A_{\text {sat }}$ and Resp by $58.9 \%$ and $37.7 \%$, respectively. $V_{\text {cmax }}$ and $C E$ showed similar patterns to $A_{\text {sat }}$ : with limited influence by ABA and BR treatments alone. However, the $\mathrm{ABA}$ and $\mathrm{BR}$ combined treatments affected $V_{\mathrm{cmax}}$ and $C E$ significantly $(P \leq 0.05)$, especially for $0.01 \mathrm{mM} \mathrm{ABA}$ and $2 \times 10^{-4} \mathrm{mM} \mathrm{BR}$, and $0.1 \mathrm{mM} \mathrm{ABA}$ and $2 \times 10^{-4} \mathrm{mM}$ BR treatments. $J_{\max }$ was higher in all treatments than the control, especially $0.01 \mathrm{mM} \mathrm{ABA}$ and $2 \times 10^{-4} \mathrm{mM} \mathrm{BR}$. $V_{\text {TPU }}$ was higher in all treatments than the control except $0.01 \mathrm{mM}$ ABA and $0.2 \times 10^{-4} \mathrm{mM}$ BR; $0.1 \mathrm{mM} \mathrm{ABA}$ and $2 \times 10^{-4} \mathrm{mM}$ BR gave the largest increase among treaments.

\section{Chlorophyll fluorescence}

$\mathrm{F}_{\mathrm{o}}$ was not significantly affected by treatments, but significant $(P \leq 0.05)$ differences in $\mathrm{F}_{\mathrm{m}}$ and $\mathrm{F}_{\mathrm{v}}$ were observed (Figure 4). $F_{m}$ and $F_{v}$ tended to increase from ABA alone to high ABA and high BR treatments, which were higher than the control. ABA alone, high $\mathrm{BR}$, and $0.1 \mathrm{mM} A B A$ and $2 \times 10^{-4} \mathrm{mM}$ BR were higher than the others in $\mathrm{F}_{\mathrm{m}}$ and $\mathrm{F}_{\mathrm{v}}$. ABA caused a significant $(P \leq 0.05)$ decrease in $\mathrm{F}_{\mathrm{v}} / \mathrm{F}_{\mathrm{m}}$ and $\mathrm{BR}$ caused a significant $(P \leq 0.05)$ increase in $F_{v} / F_{m}$ compared to the control. When the two hormones were applied together, the ABA effect was counteracted by $B R$, and $F_{v} / F_{m}$ showed higher values than when $\mathrm{BR}$ was applied alone. ABA alone, BR alone and high $\mathrm{ABA}$ and high $\mathrm{BR}$ treatments were significantly $(P \leq 0.05)$ higher (Figure 5$) . \mathrm{F}_{\mathrm{v}} / \mathrm{F}_{\mathrm{o}}$ patterns strongly resembled that of $\mathrm{F}_{\mathrm{m}} / \mathrm{F}_{\mathrm{o}} . \mathrm{F}_{\mathrm{m}} / \mathrm{F}_{\mathrm{o}}$ expresses the basal quantum yield of non-photochemical processes. From Figure 5, there were no notable differences between the control and treatments. All these results indicated that hormone treatments change the chlorophyll fluorescence of $L$. chinensis leaves and hence influence the photosynthesis.

\section{Discussion and conclusions}

At present, global environment and crop production research lend special significance to improving plant photosynthesis, plant production and biomass through 
Table 2 Photosynthetic parameters of $L$. chinensis in response to light under ABA and BR treatments

\begin{tabular}{|c|c|c|c|c|}
\hline Treatment & $Q_{E}$ & $A_{\max }\left[\mu \mathrm{mol} \mathrm{m}{ }^{-2} \mathrm{~s}^{-1}\right]$ & $L C P$ & $L S E$ \\
\hline Control & $0.02 \pm 0.00 d^{1}$ & $10.33 \pm 0.93 c$ & $78.66 \pm 1.85 a$ & $502.80 \pm 10.77 a$ \\
\hline ABA & $0.04 \pm 0.00 c$ & $9.96 \pm 0.85 c$ & $52.96 \pm 1.94 b$ & $283.10 \pm 9.56 b$ \\
\hline High BR & $0.07 \pm 0.00 b$ & $13.26 \pm 0.67 b c$ & $52.28 \pm 1.25 b$ & $255.20 \pm 8.74 b$ \\
\hline$A B A+$ low $B R$ & $0.06 \pm 0.00 b$ & $13.88 \pm 0.53 b c$ & $54.21 \pm 1.68 b$ & $295.80 \pm 10.65 b$ \\
\hline $\mathrm{ABA}+$ medium $\mathrm{BR}$ & $0.07 \pm 0.00 b$ & $13.64 \pm 0.78 b c$ & $45.08 \pm 1.34 c$ & $548.40 \pm 11.28 a$ \\
\hline$A B A+$ high $B R$ & $0.11 \pm 0.00 a$ & $16.86 \pm 0.91 a$ & $25.07 \pm 1.25 d$ & $175.70 \pm 10.34 c$ \\
\hline High $A B A+$ high $B R$ & $0.11 \pm 0.00 a$ & $14.14 \pm 0.94 b$ & $24.58 \pm 0.99 d$ & $157.00 \pm 10.26 c$ \\
\hline
\end{tabular}

(ABA: abscisic acid; BR: brassinolide; $Q_{E}$ : high energy state quenching; $A_{\text {max }}$ the maximum net photosynthesis; LCP: light compensation point; LSE: light saturation estimate. ${ }^{1}$ : Different letters with a column indicate significate difference at $\mathrm{P} \leq 0.05$ ).

enhancing plant's ability to resist saline-alkaline, drought and other environment stresses. Amongst others, plant growth regulators and related compounds have shown beneficial functions on the enhancement of plant growth performance and great potential to help realize those above mentioned goals.

Our experiment results indicated that the $0.01 \mathrm{mM}$ ABA treatment inhibited leaf photosynthetic rate, stomatal conductance, and transpiration rate of mature L. chinensis to a certain extent, which are consistent with the results of former studies with inhibition of ABA on leaf gas exchange have been observed in several plant species Vardhini and Ramr (1998, Hou and Li 2001). We also observed that the application of $0.01 \mathrm{mM}$ ABA treatment reduced the plant height and leaf quantity of the studied L. chinensis populations. However, it increased plant density, fresh mass, plant length and length width ratio of L. chinensis populations. Similar results have been reported by Saab et al. (1990) on the effects of ABA application on the growth of maize seedlings. Saab et al. (1990) found that ABA could promote the growth of maize seedling root, and inhibit stem and leaf growth under the water stress or water shortage condition. Moreover, we also found the special physiological effect of ABA treatment alone on other leaf photosynthetic parameters, such as an increase in the maximum RUBP carboxylation rate, leaf respiration rate, maximum electron transport, and maximum triose-phosphate utilization rate of $L$. chinensis leaves and a reduction in the light compensation point and light saturation estimates. The results of leaf chlorophyll fluorescence measurements suggest that ABA treatment enhanced anti-photoinhibition and the ability to resist harmful environments in L. chinensis. Overall, despite slightly reduction in plant height and leaf number per shoot, the gas exchange and chlorophyll fluorescence data indicate that the application of ABA alone enhanced leaf photosynthetic activities and $\mathrm{CO}_{2}$ assimilation rate.

$\mathrm{BR}$ is another important plant growth regulator, which has profound impacts of leaf photosynthesis and plant performance. The results of previous experiments suggest that $\mathrm{BR}$ improve leaf carbon assimilation rate through increasing the content of chlorophyll, which is the light harvesting machine of plant photosynthesis. Moreover, it has also showed that BR application could significantly alleviate the impacts of various abiotic stresses. For instance, BR treatment enhanced photosynthetic performance of cotton seedlings under $\mathrm{NaCl}$ stress Ding et al. (1995; Xiao et al. 2007; Chen et al. 2007; Shu et al. 2011). For cucumber seedlings, BR treatment has also been found to promote the occurrence of new roots and the formation of lateral roots Bao et al. (2004). Similar results were obtained in our experiment; BR

Table 3 Photosynthetic parameters of $L$. chinensis in responses to $\mathrm{CO}_{2}\left(C_{\mathrm{i}}\right)$ under $\mathrm{ABA}$ and $\mathrm{BR}$ treatments

\begin{tabular}{|c|c|c|c|c|c|c|c|}
\hline Treatment & $\begin{array}{l}A_{\text {sat }} \\
{\left[\mu \mathrm{mol} \mathrm{m} \mathrm{m}^{-2} \mathrm{~s}^{-1}\right]}\end{array}$ & CCP & Resp & $V_{\text {cmax }}$ & $J_{\max }$ & $V_{\text {TPU }}$ & $C E$ \\
\hline Control & $31.16 \pm 3.61 \mathrm{~cd}^{1}$ & $30.00 a$ & $18.30 \pm 1.15 c$ & $33.50 \pm 2.82 \mathrm{de}$ & $140.00 \pm 2.67 \mathrm{e}$ & $22.70 \pm 1.67 c$ & $0.04 \pm 0.00 c$ \\
\hline $\mathrm{ABA}$ & $27.57 \pm 4.25 d$ & $30.00 a$ & $18.40 \pm 1.29 c$ & $33.50 \pm 2.30 \mathrm{de}$ & $162.00 \pm 2.81 d$ & $28.20 \pm 1.29 b$ & $0.04 \pm 0.00 c$ \\
\hline High BR & $31.27 \pm 2.56 \mathrm{~cd}$ & $30.00 a$ & $17.20 \pm 1.05 \mathrm{~cd}$ & $34.10 \pm 2.64 d$ & $191.00 \pm 3.11 c$ & $32.70 \pm 1.87 a$ & $0.04 \pm 0.00 c$ \\
\hline$A B A+$ low $B R$ & $32.06 \pm 3.17 c$ & $30.00 a$ & $23.10 \pm 2.00 a b$ & $37.90 \pm 2.71 c$ & $199.00 \pm 3.09 c$ & $27.00 \pm 1.48 b$ & $0.07 \pm 0.00 \mathrm{~b}$ \\
\hline $\mathrm{ABA}+$ medium $\mathrm{BR}$ & $33.19 \pm 3.89 c$ & $30.00 a$ & $24.60 \pm 1.65 a$ & $45.20 \pm 2.35 b$ & $237.00 \pm 3.47 b$ & $20.40 \pm 1.95 d$ & $0.13 \pm 0.00 \mathrm{ab}$ \\
\hline$A B A+$ high $B R$ & $49.51 \pm 4.06 a$ & $30.00 a$ & $25.20 \pm 1.45 a$ & $51.90 \pm 2.88 \mathrm{a}$ & $262.00 \pm 3.55 a$ & $25.90 \pm 1.55 b c$ & $0.15 \pm 0.00 \mathrm{a}$ \\
\hline High $A B A+$ high $B R$ & $41.93 \pm 3.73 b$ & $30.00 a$ & $20.80 \pm 1.82 b$ & $51.10 \pm 2.63 a$ & $236.00 \pm 3.17 b$ & $32.80 \pm 1.73 a$ & $0.14 \pm 0.00 \mathrm{ab}$ \\
\hline
\end{tabular}

ABA: abscisic acid; BR: brassinolide; $A_{\text {sat }}$ : light-saturated rate of net photosynthesis; $C \mathrm{CP}: \mathrm{CO}_{2}$ compensation point; Resp: respiration; $V_{\text {cmax: }}$ maximum RUBP carboxylation rates; $J_{\text {max }}$ : the maximum electron transport; $V_{\text {TPU: }}$ maximum triose-phosphate utilization; $C E$ : carboxylation efficiency calculated from the data of photosynthetic response to $\mathrm{CO}_{2} \cdot{ }^{1}$ : Different letters with a column indicate significate difference at $P \leq 0.05$. 


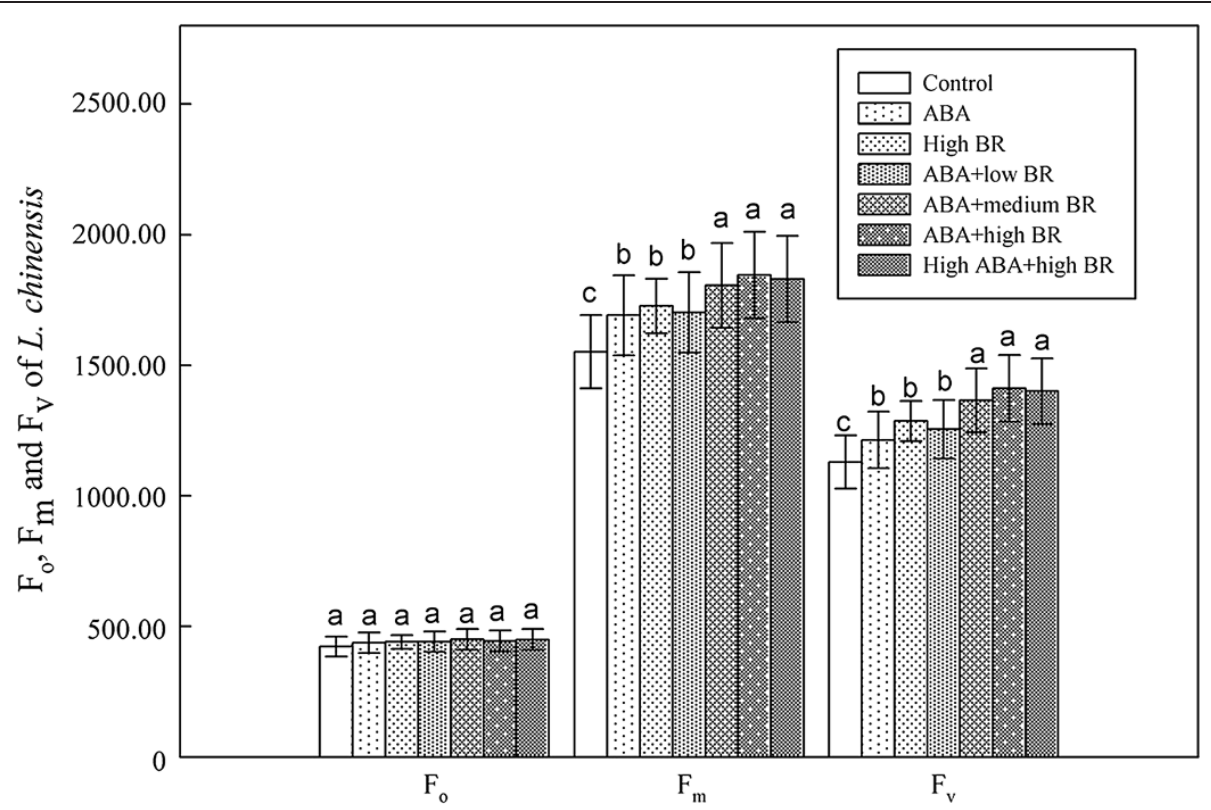

Figure 4 Changes in $F_{o}, F_{m}$ and $F_{v}$ of $L$. chinensis under $A B A$ and $B R$ treaments ( $F_{o}$ : initial fluorescence; $F_{m}$ : maximum fluorescence; $F_{v}$ : variable fluorescence).

treatment $\left(2 \times 10^{-4} \mathrm{mM}\right)$ alone increased the photosynthetic carboxylation capacity and $\mathrm{CO}_{2}$ assimilation rate. Subsequently, BR treatment enhaned the plant density, height and biomass of the studied $L$. chinensis populations. As a saline alkali grassland rhizomatous plant, the occurrence of new and lateral roots is conducive for the growth as well as rhizome breeding of $L$. chinensis. The observed significant treatment effects of BR on L. chinensis may attribute to the stimulation of BR on the formation of new and lateral roots, which will not only directly enhance rhizome breeding and population density, but also indirectly improve plant water and nutrient uptake.

The effects of ABA or BR alone treatment on leaf gas exchange and plant performance have been conducted

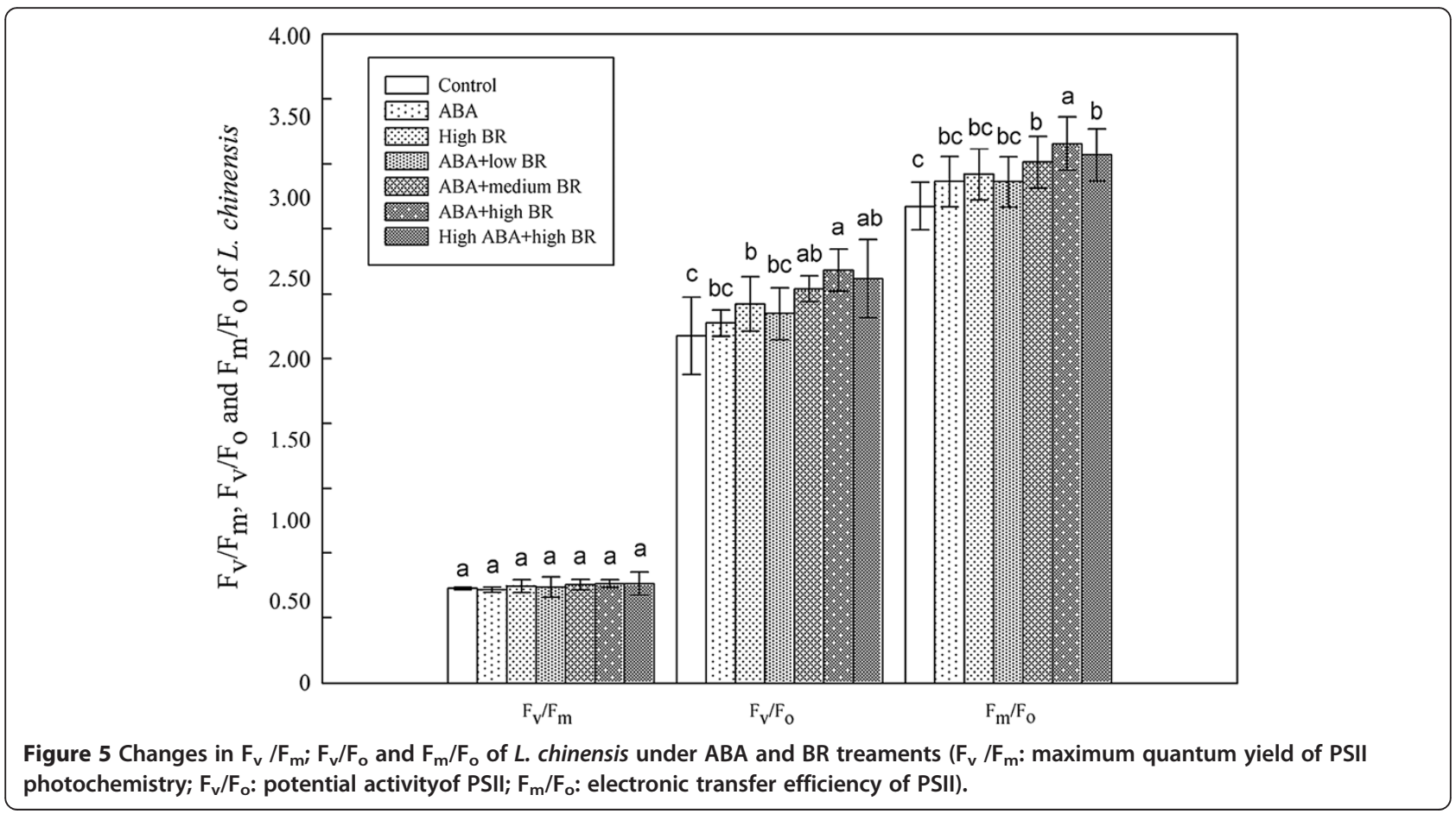


in various plants. However, the impacts of $\mathrm{ABA}$ and $\mathrm{BR}$ mixture on plant growth have been rarely tested, especially in perennial grasses. We studied the combined impacts of various $\mathrm{ABA}$ and $\mathrm{BR}$ mixtures on the leaf carboxylation capacity and growth performance of $L$. chinensis. The experimental results showed that ABA and BR treatments mixed in different proportions are evidently superior to treatments with ABA alone and $\mathrm{BR}$ alone on the enhancement of photosynthetic assimilation capacity and growth performance. The ABA and BR mixture treatments expressed not simply add up of the impacts of $\mathrm{ABA}$ and $\mathrm{BR}$ treatment alone, but showed compensatory effects between ABA and BR. This phenomenon is especially significant for the mixture of $0.01 \mathrm{mM} \mathrm{ABA}$ and $2 \times 10^{-4} \mathrm{mM} \mathrm{BR}$, which evidently increased $P_{\mathrm{N}}, g_{\mathrm{s}}$ and WUE, as well as $A_{\text {max }}, A_{\text {sat, }}$ $R$ esp, $V_{\text {cmax }}, J_{\max }, V_{\mathrm{Tpu}}, C E$ and quantum efficiency of PSII, and reduced the LCP and LSE. As a result of enhancement in photosynthetic capacity and $\mathrm{CO}_{2}$ assimilation rate, plant density, height and biomass were significantly increased in L. chinensis. Despite unclear in the underlying physiological mechanisms of the impacts of ABA and BR treatments on leaf photosynthetic capacity, the observed obvious effects of ABA and BR mixture on plant performance may attribute, to some extent, the compensatory impacts of ABA and BR treatment. For instance, BR application could improve root system and nutrient uptake, whereas ABA treatment enhanced photosynthetic capacities.

This experiment studied the impacts of ABA alone, $\mathrm{BR}$ alone and various mixture of $\mathrm{ABA}$ and $\mathrm{BR}$ on the performance of $L$. chinensis. Treatments of ABA alone or BR alone enhanced plant photosynthetic capacity and growth performance, however those effects were more significant when ABA and BR were implied in mixture. We proposed that there are compensatory effects between $\mathrm{ABA}$ and $\mathrm{BR}$ on regulating plant photosynthetic capacity and growth performance. Moreover, the experimental results provides evidence for enhancing the stress resistance of perennial plant populations and also builds a basis for recovering grasses growing under saline and alkaline conditions.

\section{Abbreviations}

ABA: Abscisic acid; $A_{\text {max }}$ : The maximum net photosynthetic rate; $A_{\text {sat: }}$ Lightsaturated rate of net photosynthesis; BR: Brassinolide; $C_{a}$ : Atmospheric $\mathrm{CO}_{2}$ concentration; $\mathrm{C}_{\mathrm{i}}$ : Intercellular $\mathrm{CO}_{2}$ concentration; $\mathrm{CCP}$ : $\mathrm{CO}_{2}$ compensation point; $\mathrm{CE}$ : Carboxylation efficiency calculated from $\mathrm{CO}_{2}$ response curve; E: Transpiration rate; $F_{0}$ : Initial fluorescence; $F_{m}$ : Maximum fluorescence; $F_{\mathrm{v}}$ : Variable fluorescence; $g_{\mathrm{s}}$ : Stomatal conductance; $J_{\text {max }}$ : The maximum electron transport rate; LCP: Light compensation point; LSE: Light saturation estimate; $P_{N}$ : Net photosynthetic rate; $Q_{A}$ : Primary electron acceptor; $Q_{E}$ : High energy state quenching; Resp: Respiration; $V_{c \text { max }}$ : Maximum RUBP carboxylation rate; $V_{\text {TPU: }}$ Maximum rate of triose- phosphate utilization; WUE: Water use efficiency.
}

\section{Competing interests}

The authors declare that they have no competing interests.

\section{Authors' contributions}

YJH and LXS: designed the experiments, carried out the laboratory experiments, analyzed the data, interpreted the results and wrote the paper. WS: co-designed the dispersal and colonization experiments, and co-worked on associated data collection and their interpretation. JXG: co-designed experiments, involved in data analyses, interpretation, and presentation. All authors read and approved the final manuscript.

\section{Acknowledgements}

This research was supported by the National Natural Science Foundation of China (No. 31270366, 30870238, 31270445), Natural Science Foundation of Jilin Province (No. 20100577) and Program for New Century Excellent Talents in University (NCET-12-0814).

\section{Author details}

${ }^{1}$ Key Laboratory for Vegetation Ecology, Ministry of Education, Institute of Grassland Science, Northeast Normal University, Changchun 130024, China. ${ }^{2}$ School of Life Sciences, Changchun Normal University, Changchun 130032 China.

Received: 22 September 2011 Accepted: 2 April 2013

Published: 2 October 2013

\section{References}

Bajguz A, Hazat S (2009) Effects of brassinosteroids on the plant responses to environmental stress. Plant Physiol Biochem 47:1-8

Bao F, Shen J, Brady SR, Muday GK, Asami T, Yang Z (2004) Brassinosteroids interact with auxin to promote lateral root development in Arabidopsis. Plant Physiol 134:1624-1631

Chen JH, Mao D, Ma ZY (2006) Physiological Characteristics of Leaves of Bamboo Phyllostachvs pubescens. J Cent S Forest Univ 6:77-81

Chen LX, Li YH, Zheng FE (2007) Effect of brassinosteroids on soybean resistance to phytophthora sojae. Soybean Sci 5:713-727

Ding JX, Ma GR, Huang SQ, Zhao YM (1995) Studies on physiological effects of epiBR on cucumber (Cucumis sativus L). J Zhejiang Agric Univ 6:615-621

Dordas CA, Sioulas C (2007) Safflower yield, chlorophyll content, photosynthesis and water use efficiency response to nitrogen fertilization under rain fed conditions. Ind Crop Prod 1:75-85

Field CB, Ball JT, Berry JA (eds) (1989) Plant Physiological Ecology. Chapman and Hall Press, New York, pp 209-253

Franks PJ, Farquhar GD (2001) The Effect of Exogenous Abscisic Acid on Stomatal Development, Stomatal Mechanics, and Leaf Gas Exchange in Tradescantia virginiana. Plant Physiol 2:935-942

Hou LP, Li ML (2001) Progress of Studies on the Plant Growth Promoting Mechanism of Brassinolide(BR). Chinese Bull Bot 5:560-566

Jia HS, Lu CM (2003) Effects of abscisic acid on photo inhibition in maize plants. Plant Sci 165:1403-1410

Khripach V, Zhabinskii V, Groot AD (2000) Twenty years of Brassinosteroids: Steroidal plant hormones waeant better crops for the XXI century. Ann Bot 86:441-447

Krouk G, Ruffel S, Rodrigo A, Gutie'rrez RA (2011) A framework integrating plant growth with hormones and nutrients. Trends Plant Sci 4:178-182

Li JD, Zheng HY (eds) (1997) The Control of Alkalinized-Salinized Grasslands in the Songnen Plain and Their Mechanisms. Science Press, Beijing, pp 5-102

Li X, Zhang L, He X (2006) Effects of abscisic acid on photosynthetic characteristics and antioxidant enzyme activities of wheat seedlings. Chinese J App Ecol 5:822-826

Liu DB, Wei JY, Li SP, Cui BM, Peng M (2008) Effects of Brassinolid on chillingresistance in banana Seedlings. Bull Bot Res 2:195-221

Long SP, Bernacchi CJ (2003) Gas exchange measurements, what can they tell us about the underlying limitations to photosynthesis? Procedures and sources of error. J Exp Bot 54:2393-2401

Mawson BT, Colman B, Cummin WR (1981) Abscisic Acid and Photosynthesis in Isolated Leaf Mesophyll Cell. Plant Physiol 2:233-236

Mclaren JS, Smith H (1977) Effect of abscisic acid on photosynthetic products of Lemna minor. Phytochemistry 2:219-221

Olsson T, Leverenz JW (1994) Non-uniform stomatal closure and the apparent convexity of the photosynthetic photon flux density response curve. Plant Cell Environ 17:701-710

Peleg Z, Blumwald E (2011) Hormone balance and abiotic stress tolerance in crop plants. Curr Opin Plant Biol 14:290-295 
Prioul JL, Chartier P (1997) Partitioning of transfer and carboxylation components of intracellular resistance to photosynthetic $\mathrm{CO}_{2}$ fixation: A critical analysis of the methods used. Ann Bot 41:789-800

Saab IN, Sharp RE, Pritchard J, Voetberg GS (1990) Increased endogenous abscisic acid maintains primary root growth and inhibits shoot growth of maize seedlings at low water potentials. Plant Physiol 93:1329-1336

Šafránková I, Hejnák V, Stuchlíková K (2007) The effect of abscisic acid on rate of photosynthesis and transpiration in six barley genotypes under water stress. Cereal Res Commun 2:1013-1016

Sankhla N, Huber W (1974) Effect of Abscisic Acid on the Activities of Photosynthetic Enzymes and ${ }^{14} \mathrm{CO}_{2}$ Fixation Products in Leaves of Pennisetum typhoides Seedlings. Physiol Plant 4:291-294

Shi LX, Guo JX (2006) Changes in photosynthetic and growth characteristics of Leymus chinensis community along the retrogression on the Songnen grassland in northeastern China. Photosynthetica 4:542-547

Shu HM, Guo SQ, Shen XL, Ni WC (2011) Cotton physiology affected by brassinosteroid under $\mathrm{NaCl}$ stress. Jiangsu J of Agr Sci 6:1198-1202

Vardhini BV, Ramr SS (1998) Effect of brassinosteroids on growth, metabolite content and yield of Arachishy pogaea. Phytochemistry 6:927-930

Wang P, Zhou DW (2004) Research on the Utilization Modes of Hordeum Brevisulatum and Leymus Chinensis Based on the Comparison of Photosynthesis and Transpiration. Grassland of China 26:3

Wu CT (2010) The Interaction and Relationship between Nitric Oxide and Phytohormone. Genom App Biol 6:1169-1176

Wu YY, Li PP, Zhao YG, Wang JZ, Wu XG (2007) Study on photosynthetic characteristics of Orychophragmus violaceus related to shade-tolerance. Sci Hortic 113:173-176

Xiao L, Pang RH, Cai RX, Yu P, Huang XH, Wang L (2007) Physiological Effect and Yield Increase Action after Spraying BR in Rice Early Blooming Stage. J Anhui Agri Sci 11:3317-3330

Zhou BY, Guo ZF, Lin L (2006) Effects of Abscisic Acid Application on Photosynthesis and Photochemistry of Stylosanthes guianensis under Chilling Stress. Plant Growth Regul 3:195-199

doi:10.1186/1999-3110-54-42

Cite this article as: Hu et al:: Effects of abscisic acid and brassinolide on photosynthetic characteristics of Leymus chinensis from Songnen Plain grassland in Northeast China. Botanical Studies 2013 54:42.

\section{Submit your manuscript to a SpringerOpen ${ }^{\circ}$ journal and benefit from:}

- Convenient online submission

- Rigorous peer review

- Immediate publication on acceptance

- Open access: articles freely available online

- High visibility within the field

- Retaining the copyright to your article

Submit your next manuscript at $\gg$ springeropen.com 